\title{
Primary Writing Tremor Responds to Unilateral Thalamic Deep Brain Stimulation
}

\author{
Primer Yazma Tremoru Ünilateral Talamik Derin Beyin Stimülasyonuna \\ Cevap Verir
}

\author{
Mark LYONS ${ }^{1}$, Natalya SHNEYDER ${ }^{2}$, Virgilio EVIDENTE ${ }^{2}$ \\ ${ }_{1}^{1}$ Mayo Clinic Arizona, Department of Neurological Surgery, Phoenix/AZ, USA \\ 2Mayo Clinic Arizona, Department of Neurology, Phoenix/AZ, USA
}

Correspondence address: Mark LYONS / E-mail: lyons.mark2@mayo.edu

\begin{abstract}
Primary writing tremor is a task associated tremor which occurs during and interferes with handwriting. Considered in most cases to be a nonprogressive disorder, a number of patients are significantly debilitated by the disease. The pathophysiology of the disorder is not fully understood, but felt to represent a variant of either essential tremor or dystonia versus a separate entity. Treatment has been limited to medications, writing devices and botulinum toxin type A for most patients. Recently, deep brain stimulation has been reported in a few patients as an effective option for those patients with medically refractory symptoms. We report our experience in a patient with primary writing tremor who underwent successful thalamic deep brain stimulation, discuss the current theories on the pathophysiology of the disorder and review the current literature of deep brain stimulation for refractory primary writing tremor.
\end{abstract}

KEYWORDS: Primary writing tremor, Deep brain stimulation, Thalamus

öz

Primer yazma tremoru elle yazma sırasında oluşan ve bu işlemi olumsuz etkileyen, işlemle ilişkili bir tremordur. Çoğu vakada nonprogresif bir bozukluk olduğu düşünülmektedir ama bazı hastalar bu hastalık nedeniyle ciddi maluliyet durumu yaşar. Bozukluğun patofizyolojisi tam olarak anlaşılmamaktadır, ama ayrı bir antite yerine esansiyel tremor veya distoninin bir varyantı olduğu düşünülmektedir. Tedavi çoğu hastada ilaçlar, yazmaya yardımcı cihazlar ve botulinum toksini tip A ile sınırlıdır. Son zamanlarda derin beyin stimülasyonu tıbben refrakter belirtileri olan bazı hastalarda etkili bir seçenek olarak bildirilmiştir. Başarılı talamik derin beyin stimülasyonu yapılan bir primer yazma tremorlu hastayla deneyimimizi bildiriyor, bozukluğun patofizyolojisiyle ilgili mevcut teorileri açıklıyor ve refrakter primer yazma tremoru için derin beyin stimülasyonuyla ilgili güncel literatürü gözden geçiriyoruz.

ANAHTAR SÖZCÜKLER: Primer yazma tremoru, Derin beyin stimülasyonu, Talamus

\section{INTRODUCTION}

Primary writing tremor (PWT) is considered a task-specific tremor predominantly affecting handwriting. The condition was first described by Rothwell in 1979 and was noted to appear during pronation of the forearm which resulted in a pronation/supination tremor (17). This tremor occurred with handwriting and was not seen during other arm motions. Two specific types of PWT have been described. Type A PWT, also referred to as task-induced tremor, occurs with writing only. Type B PWT, also referred to as positionally sensitive tremor, occurs simply when the patient assumes the hand position for writing (17). The pathophysiology in not known, but PWT tremor is generally felt to be a variant of essential tremor (ET), dystonia or separate neurological entity $(1,5,7,9)$. Primary writing tremor is most often unilateral, but bilateral PWT has been reported (10). Severe forms of the disorder can be very disabling and can be refractory to medications and physical measures.

\section{MATERIAL and METHODS}

We report a 66-year-old female with a six-year history of progressive task-specific action tremor affecting only her dominant right hand. She had a positive family history for ET affecting her mother and brother. The patient was diagnosed with PWT by two movement disorders specialists. Though her tremor was focal and task-specific, she was severely disabled by it given her profession as a secretary. On initial examination at our institution at age 66 , she presented only with a severe right hand tremor during writing, but no tremor with other actions of the right hand. Her writing was virtually illegible (Figure 1). No resting or postural tremor was seen in any extremity. The rest of her neurological examination was unremarkable. Surface electromyography (EMG) studies revealed a prominent $5 \mathrm{~Hz}$ tremor of her right upper limb muscles (distal more than proximal) during writing with alternating contraction of antagonistic muscles; no signs of dystonia (i.e., co-contraction of antagonistic muscles) were noted. Prior treatment with wrist weights and clonazepam 
proved ineffectual. She also developed significant sleepiness and cognitive slowing with clonazepam. She was offered more drug options for her PWT, though she declined further pharmacotherapy given the potential side effects from the medications. Unilateral thalamic DBS targeting of the left Vim nucleus was performed using the COMPASS ${ }^{\circ}$ stereotactic system. The target coordinates were based upon the anterior and posterior commissures, thalamic height and $11.5 \mathrm{~mm}$ lateral to the ipsilateral wall of the third ventricle. The surgical procedure was performed under local anesthesia with mild conscious sedation. Microelectrode recordings were done using 3 concentric bipolar tungsten microelectrodes driven simultaneously by a hydraulic Alpha-Omega microdrive at incremental depths of 0.3 to $0.5 \mathrm{~mm}$. Intraoperative electrophysiology was performed to locate and confirm the ventral posterior border of the Vim nucleus adjacent to the sensory nucleus of the thalamus. Microelectrode recordings were followed by microstimulation in order to optimize depth and trajectory. Subsequent implantation of a Medtronic quadripolar 3387S DBS electrode was performed. Macrostimulation was done to further refine final electrode placement based upon intraoperative effect. The DBS electrode was then connected to a Medtronic Activa $\mathrm{PC}^{\circ}$ implantable pulse generator in an infraclavicular pocket. Postoperative brain MR confirmed placement of the electrode tip in the Vim nucleus of the left thalamus. At the initial programming one week following surgery, the patient reported complete resolution of her writing tremor. Programming parameters were as follows: case positive, contact 3 negative, amplitude 1.5 volts, pulse width $60 \mathrm{~ms}$, and rate $180 \mathrm{~Hz}$. At last follow-up six months post-DBS, the patient continues to report complete relief of her symptoms, with no side effects from unilateral thalamic stimulation (Figure 2).

\section{DISCUSSION}

There remains controversy as to the etiology of PWT. Whether it is as form of ET or dystonia or possibly a separate disorder is unclear. Some authors have reported PWT to be responsive to propranolol, primidone and alcohol, suggesting that the disorder may be more likely a variant of ET (2,5,6,8-10). Conversely, other investigators have described patients responsive to botulinum toxin type $A$ (BoNT-A) and anticholinergic medications and have suggested that PWT may be a form of dystonia $(14,18,19)$. However, patients with tremor, such as Parkinson's tremor, can also be responsive to BoNT-A, as well as anticholinergic agents. Writing devices have also been used in patients for whom oral medications have been ineffective and with encouraging results (8). Primary writing tremor can sometimes be mistaken as writer's cramp, though the latter is generally felt to be a separate entity from PWT $(2,9,12)$. Writer's cramp presents as a task-specific dystonia with abnormal hand posturing during writing, but is not uniformly accompanied by tremor. In addition, electromyographic studies have demonstrated a decrease in presynaptic inhibition and no H-reflex in writer's cramp, as opposed to PWT in which disynaptic, presynaptic and reciprocal inhibition are normal (9). On surface EMG, PWT presents with regular rhythmic oscillations with alternate contraction of antagonistic muscles. Whereas, patients with writer's cramp and other focal dystonias will present with cocontraction of antagonistic muscles.

Although generally considered to be a nonprogressive disease, PWT can be quite incapacitating for some patients (1). Medical treatment with anticholinergic agents, primidone and propranolol can be effective in up to $60 \%$ of patients, but the side effects from the medications can be limiting (1). Some authors have reported success with BoNT-A in small numbers of patients, but the resultant hand weakness can be troubling and disabling $(3,4,11,14,15,20,21)$. The surgical treatment of PWT with deep brain stimulation may offer an alternative to those patients with significant medically refractory PWT. In 1982, Ohye and colleagues reported three patients who underwent thalamotomy of the ventralis intermedius (Vim) nucleus for medically refractory PWT, with complete relief of symptoms (13). However, reports of long-term follow-up of PWT post-thalamotomy are lacking. Given the potential progressive nature of PWT with age, as seen in ET, the fixed lesions created with thalamotomy mat result in possible recurrence of symptoms. There have been only two reports
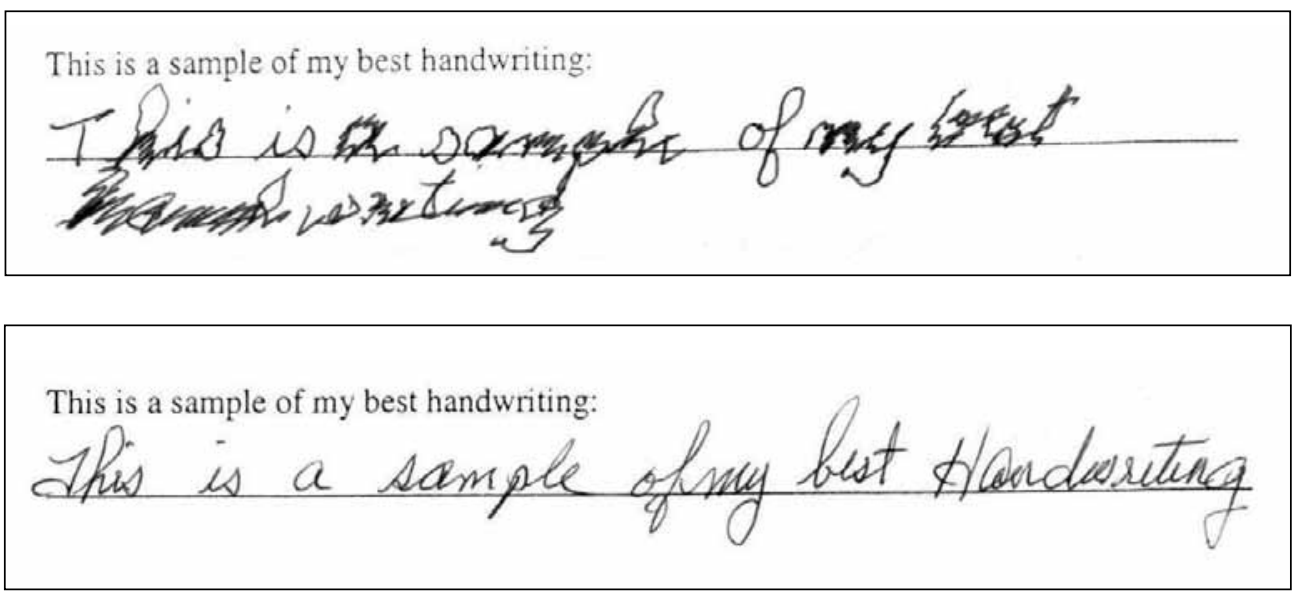

Figure 1: Primary writing tremor handwriting preoperatively.

Figure 2: Primary writing tremor handwriting 6 months postoperatively. 
of successful DBS of PWT targeting the thalamic Vim nucleus $(11,16)$ and one report targeting the posterior subthalamic nucleus (2).

Our patient was diagnosed with task-specific ET occurring primarily on writing and affecting only her dominant hand. As Bain el al. discussed, PWT may occur sporadically or inherited as an autosomal dominant trait (1). Although age of symptom onset in our patient was older than the mean age described by Bain et al. (60 versus 50 years old), she had a strongly positive family history of ET. As noted in the two other reports of thalamic DBS for refractory PWT, our patient had effectively complete relief of her tremor. Currently, oral medications, writing devices, wrist weights and BoNT-A injections are the initial treatment options for patients with symptomatic PWT. While the pathophysiology of PWT is incompletely understood, given its immediate and potentially complete resolution with thalamic DBS, it more likely is a variant of ET than a form of focal dystonia. Whereas ET patients often have immediate and dramatic improvement of their tremor post-DBS, patients with focal dystonia often have a delayed response and less dramatic improvement in the immediate post-operative period. Our case, as the two other previous reports, suggests that unilateral thalamic DBS may offer a reasonable and safe treatment option for medically refractory patients suffering with PWT.

\section{REFERENCES}

1. Bain PG, Findley LJ, Britton TC, Rothwell JC, Gresty MA, Thompson PD, Marsden CD: Primary writing tremor. Brain 118(Pt6 6):1461-1472, 1995

2. Blomstedt $P$, Fytagoridis A, Tisch S: Deep brain stimulation of the posterior subthalamic area in the treatment of tremor. Acta Neurochir 151:31-36, 2009

3. Chen R, Karp BI, Goldstein SR, Bara-Jimenez W, Yaseen $Z$, Hallett M: Effect of muscle activity immediately after botulinum toxin injection for writer's cramp. Mov Disord 14:307-312, 1999

4. Cole R, Hallett M, Cohen LG: Double-blind trial of botulinum toxin for treatment of focal hand dystonia. Mov Disord 10:466-471, 1995

5. Deuschl G, Bain P: Deep brain stimulation for trauma: Patient selection and evaluation. Mov Disord 17(Suppl 3):S102-S111, 2002

6. Elble RJ: Diagnostic criteria for essential tremor and differential diagnosis. Neurology 54(Suppl 4):S2-S6, 2000
7. Elble RJ, Moody C, Higgins C: Primary writing tremor. A form of focal dystonia? Mov Disord 5:118-1126, 1990

8. Espay AJ, Hung SW, Sanger TD, Moro E, Fox SH, Lang AE: A writing device improves writing in primary writing tremor. Neurology 64:1648-1650, 2005

9. Hai $C$, Wang $Y P$, Wei $H$, Sun $Y$ : Advances in primary writing tremor. Parkinsonism and Relat Disord 16:561-565, 2010

10. Jimenez-Jimenez FJ, Cabrera-Valdivia F, Orti-Pareja M, Gasalla T, Tallon-Barranco A, Zurdo M: Bilateral primary writing tremor. Eur J Neurol 5:613-614, 1998

11. Minguez-Castellanos A, Carnero-Pardo C, Gomez-Camello A, Ortega-Moreno A, Garcia-Gomez T, Arjona V, Martin-Linares JM: Primary writing tremor treated by chronic thalamic stimulation. Mov Disord 14:1030-1033, 1999

12. Modugno N, Nakamura Y, Bestmann S, Curra A, Berardelli A, Rothwell J: Neurophysiological investigations in patients wit primary writing tremor. Mov Disord 21:1336-1340, 2002

13. Ohye C, Miyazaki M, Hirai T, Shibazaki T, Nakajima $H_{\text {, }}$ Nagaseki Y: Primary writing tremor treated by stereotactic selective thalamotomy. J Neurol Neurosurg Psychiatry 45:988-979, 1982

14. Papapetropoulos S, Singer C: Treatment of primary writing tremor with botulinum toxin type $A$ injections: Report of a case series. Clin Neuropharmacol 29:364-367, 2006

15. Poungvarin $\mathrm{N}$ :Writer's cramp: The experience with botulinum toxin injections in 25 patients. J Med Assoc Thai 74:239-247, 1991

16. Racette BA, Dowling J, Randle J, Mink JW: Thalamic stimulation for primary writing tremor. J Neurol 248:380-382, 2001

17. Rothwell JC, Traub MM, Marsden CD: Primary writing tremor. J Neurol Neurosurg Psychiatry 42:1106-1114, 1979

18. Singer C, Papapetropoulos S, Spielholz NI: Primary writing tremor: Report of a case successfully treated with botulinum toxin A injections and discussion of underlying mechanism. Mov Disord 20:1387-1388, 2005

19. Soland VL, Bhatia KP, Volonte MA, Marsden CD: Focal taskspecific tremors. Mov Disord 11:665-670, 1996

20. Turjanski N, Pirtosek Z, Quirk J, Anderson TJ, Rivest J, Marsden $C D$, Lees AJ: Botulinum toxin in the treatment of writer's cramp. Clin Neuropharmacol 19(4):314-320, 1996

21. Wissel J, Kabus C, Wenzel R, Klepsch S, Schwarz U, Nebe A, Schelosky L, Scholz U, Poewe W: Botulinum toxin in writer's cramp: Objective response evaluation in 31 patients. J Neurol Neurosurg Psychiatry 61(2):172-175, 1996 